OPEN ACCESS

Edited by:

Gary Tse,

Second Hospital of Tianjin Medical

University, China

Reviewed by:

Dawood Darbar

University of Illinois at Chicago,

United States

Elizabeth S. Kaufman,

The MetroHealth System,

United States

*Correspondence:

Firat Duru

firat.duru@usz.ch

Specialty section:

This article was submitted to

Cardiac Rhythmology,

a section of the journal

Frontiers in Cardiovascular Medicine

Received: 20 December 2020

Accepted: 27 January 2021

Published: 17 February 2021

Citation:

Costa S, Saguner AM, Gasperetti A, Akdis D, Brunckhorst $C$ and Duru F

(2021) The Link Between Sex

Hormones and Susceptibility to

Cardiac Arrhythmias: From Molecular

Basis to Clinical Implications.

Front. Cardiovasc. Med. 8:644279.

doi: 10.3389/fcrm.2021.644279

\section{The Link Between Sex Hormones and Susceptibility to Cardiac Arrhythmias: From Molecular Basis to Clinical Implications}

\author{
Sarah Costa ${ }^{1}$, Ardan M. Saguner ${ }^{1}$, Alessio Gasperetti ${ }^{1,2}$, Deniz Akdis ${ }^{1}$, \\ Corinna Brunckhorst ${ }^{1}$ and Firat Duru ${ }^{1,3 *}$ \\ ${ }^{1}$ Arrhythmia and Electrophysiology, Department of Cardiology, University Heart Center, Zurich, Switzerland, ${ }^{2}$ Cardiac \\ Arrhythmia Service, Department of Cardiology, Johns Hopkins Hospital, Baltimore, MD, United States, ${ }^{3}$ Center for Integrative \\ Human Physiology, University of Zurich, Zurich, Switzerland
}

It is well-known that gender is an independent risk factor for some types of cardiac arrhythmias. For example, males have a greater prevalence of atrial fibrillation and the Brugada Syndrome. In contrast, females are at increased risk for the Long QT Syndrome. However, the underlying mechanisms of these gender differences have not been fully identified. Recently, there has been accumulating evidence indicating that sex hormones may have a significant impact on the cardiac rhythm. In this review, we describe in-depth the molecular interactions between sex hormones and the cardiac ion channels, as well as the clinical implications of these interactions on the cardiac conduction system, in order to understand the link between these hormones and the susceptibility to arrhythmias.

Keywords: arrhythmia, sex hormones, cardiomyopathy, channelopathy, testosterone, estrogen

\section{INTRODUCTION}

Cardiac arrhythmias encompass a wide spectrum of clinical presentations, ranging from benign extrasystoles on electrocardiogram (ECG) to arrhythmias that may pose a significant clinical threat, such as atrial fibrillation (AF), which is an important cause of stroke, and ventricular tachycardia or fibrillation (VT/VF) that can result in sudden cardiac death (SCD) (1). A significant proportion of SCD events occurs in patients without any known cardiac disease, and even in the presence of diagnosis of a cardiac disorder, current knowledge on prediction of arrhythmic risk is limited (2). It is well-known that gender is an independent risk factor for some types of cardiac arrhythmias. For example, males have a greater prevalence of AF and the Brugada Syndrome $(3,4)$. In contrast, females are at increased risk for Torsade de pointes (TdP), both in congenital and acquired Long QT Syndrome (LQTS) (5). Despite the fact that the incidence of a variety of cardiac arrhythmias differs between men and women, the underlying mechanisms of these gender differences have not been clearly identified.

The predominant factors determining gender differences are the sex hormones. These steroid hormones are known to exert their multiple physiological effects by binding to cytosolic or membrane receptors (6). One of the target organs of action of these hormones is the heart, and there is now accumulating evidence indicating that sex hormones may have a significant impact on the cardiac rhythm $(7,8)$. It was initially thought that sex hormones only had genomic actions, 
such as exerting their effects through the regulation of transcriptional processes, hence influencing gene expression after nuclear translocation (9). However, recent literature has shown that their scope of action goes well-beyond that, and encompasses non-genomic actions, as well. In fact, these hormones can acutely regulate cardiac ion channels and affect their currents, and these actions are mediated by transcriptional processes, such as RNA and protein synthesis (6-8).

In this review, we aim to describe in-depth the molecular interactions between sex hormones and the cardiac ion channels, as well as the clinical implications of these interactions on the cardiac conduction system, in order to understand the link between these hormones and the susceptibility to arrhythmias.

\section{TYPES AND FUNCTIONS OF SEX HORMONES}

Sex hormones play a key role in reproduction and sexual development. Moreover, they are also involved in other processes, such as regulating cholesterol levels and determining inflammatory response. They are produced by the gonads (ovaries and testicles) and adrenal glands. Estrogen and progesterone are the two main female sex hormones. Estrogen promotes growth of uterine tissue and breasts, maintains libido and secondary sexual characteristics in females, whereas progesterone has a significant role in the female menstruation cycle and pregnancy. The main male sex hormone is testosterone, but females also produce a small amount of this hormone. Testosterone affects many organs and has a variety of functions, including spermatogenesis, muscle growth, maturation of genitalia and bone metabolism (Figure 1).

\section{Fluctuations in Sex Hormone Levels}

The levels of sex hormones change during life as part of physiological processes. For example, the female sex hormones increase during adolescence and drop during menopause. Moreover, cyclic hormonal changes occur during the reproductive cycle. In certain situations, fluctuations of sex hormone levels can lead to health issues such as infertility, change in sexual desire, hair loss, osteoporosis, etc.

Sex hormone fluctuations also occur in the short-term. For example, there is a substantial circadian variation in the circulating levels of testosterone. Normal values for testosterone in a healthy adult male range between 300 and 1,000 ng/dL (10). The highest level of testosterone is reached in the morning, and therefore, it is recommended to determine it between 8:00 and 10:00 am in order to achieve accurate (and comparable) measurements (11). In addition, there may also be a seasonal variability of testosterone measurements. However, this is a contradictive issue, since there is both literature supporting and rejecting this hypothesis (12). After the third decade of life, men start to have $\sim 1-2 \%$ decrease of testosterone per year (13). Finally, the amount of active serum testosterone is heavily reliant on the concentrations of sex hormone-binding globulin (SHBG) and albumin, thus being subject to fluctuations in those proteins. Such changes of testosterone levels across the healthy population pose challenges in determining its effect on cardiac physiology, as values measured have to be adjusted for multiple factors, in order to have an unbiased result.

Estradiol (E2), the most potent estrogen, has the function of regulating reproductive cycles in females (Table 1, Figure 2). Evaluating estradiol levels is challenging, given that it changes widely during the menstrual cycle. Estradiol increases prior to ovulation and falls during ovulation, and there is a gradual increase of estradiol and then decrease prior to its lowest point in early menses. Moreover, it is also subject to a circadian variability, which is further affected by the menstrual cycle in post-menopausal women, estrogen levels decrease and show fluctuations (14).

\section{Sex Hormones and Exercise}

Both testosterone and estrogen play an important role in the neuromuscular adaptation to exercise in males and females. This adaptation is mediated by the hypothalamic-pituitary-gonadal (HPG) axis, which is responsible for both acute and chronic responses to exercise (15). In males, testosterone is pivotal for athletic activity during adolescence and in adulthood. While it is well-known that exercise acutely increases testosterone levels in men, its impact in the long-term is much less clear (16). Multiple cross-sectional studies have identified decreased testosterone levels in endurance and resistance athletes, as compared to controls. Furthermore, a study by Grandys et al. (17) found that testosterone levels vary significantly even within the athlete group, depending on the training period. In fact, testosterone increases during low-intensity training periods in comparison to high-intensity training periods. Conversely, in a cross-sectional study by Fitzgerald et al. (18) which compared trained cyclists to recreational cyclists, the former group had higher levels of serum testosterone than the latter. The conflicting results could be due to the retrospective nature of the studies evaluating the impact of chronic exercise. On the other hand, the few prospective studies also showed contradictory results, most likely due to differences in the training period, the magnitude of training stimulus and the volume of training load employed. In females, the acute effects of exercise training on the HPG axis are less well-known. Nindl et al. (19) have shown that estradiol may increase acutely after exercise, whereas the long-term effects of exercise still need to be determined.

\section{THE INTERACTION BETWEEN SEX HORMONES AND CARDIAC ION CHANNELS}

The differences in cardiac electrical activity between males and females had been observed with the earliest ECG recordings a century ago. In the meantime, while the scientific community has gathered a thorough understanding of the ECG as the net sum of electrical current flow of ions crossing the cardiomyocyte cell membrane, the molecular basis underlying gender differences are still largely debated (20).

The transit of ions across the cell membrane is permitted by specific transmembrane proteins, i.e., ion channels. Any 


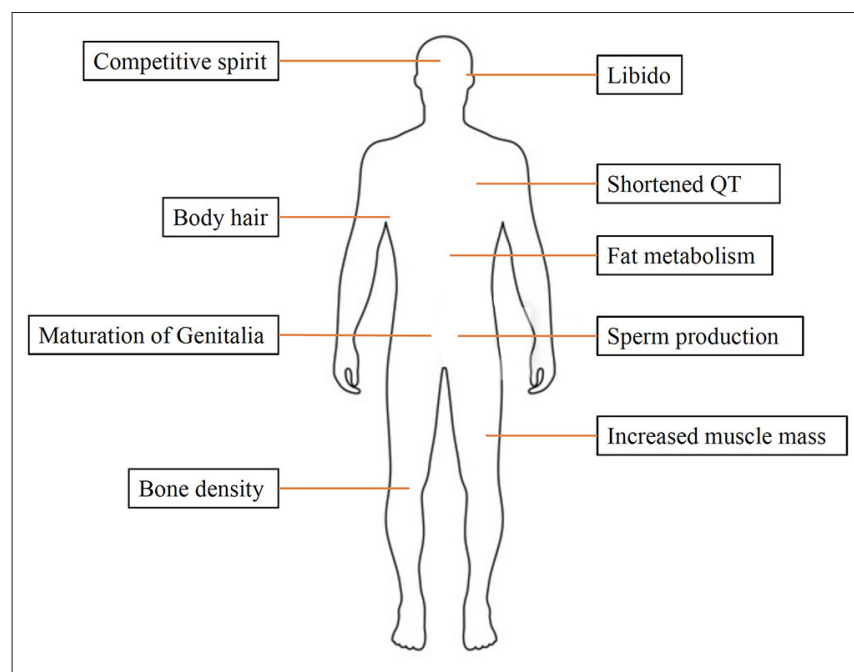

FIGURE 1 | The effects of testosterone on the human body.

TABLE 1 | Sex hormones and their biological functions.

\begin{tabular}{ll}
\hline Sex hormones & Biological functions \\
\hline Androgens & \\
Testosterone & $\begin{array}{l}\text { Development of male genitalia, increase in muscle and } \\
\text { bone mass, growth of body hair } \\
\text { Catalyzed from testosterone, considerably more potent } \\
\text { agonist of the androgen receptor }\end{array}$ \\
Androstenedione & $\begin{array}{l}\text { Precursor of testosterone, endogenous pro-hormone, } \\
\text { weak androgenic, and estrogenic activity }\end{array}$ \\
Estrogens & $\begin{array}{l}\text { Weak estrogen, precursor of estradiol } \\
\text { Estrone (E1) }\end{array}$ \\
Estradiol (E2) & $\begin{array}{l}\text { and ment estrogenic hormone: regulation of the estrous } \\
\text { of female genitalia, bone growth and density, skin health, } \\
\text { neuroprotective } \\
\text { Weak estrogen, almost undetectable in non-pregnant } \\
\text { women, high levels during pregnancy }\end{array}$ \\
Estriol (E3) & $\begin{array}{l}\text { Weak estrogen found only in pregnancy, physiological } \\
\text { function unknown }\end{array}$ \\
\hline Estetrol (E4) &
\end{tabular}

change that affects the flow of ions through these channels will have an impact on the ECG (21). The voltage-gated channels are the major ion channel group in charge of cardiac electric activity. These possess a rapid response mechanism to changes in membrane voltage and interact with each other to produce the cellular action potential (AP). In the myocardium, the rapidly activating sodium channel is the principal driver for cellular depolarization, while L-type calcium current is responsible for the plateau phase and the delayed rectifier potassium current is mostly in charge of the repolarization. These give rise to the clinically measurable QRS complex, the magnitude and dispersion of which are strongly influenced by changes to the sodium current, and the QT interval, which is dependent on the calcium and potassium currents (22). These parameters are also widely influenced by cell-cell connections, which are mediated by the connexin family of proteins at gap junctions, and therefore, ECG abnormalities often occur in diseases of the connexome (e.g., arrhythmogenic right ventricular cardiomyopathy). A decrease in cell-cell conductance typically leads to a longer QRS duration with or without terminal activation delay (23). Since the above-mentioned gender differences are not present at birth, but only appear at puberty, this has led to the hypothesis that they are dependent on sex hormone regulation (24).

Cardiac myocytes have a variety of receptors for sex hormones, specifically estrogen, progesterone and testosterone, whose activation can alter the electrical activity of the heart through modulation of ion channels. Although literature is scarce, fluctuating hormone levels can lead to changes in the behavior and expression of myocardial ion channels (Figure 3) (25).

\section{The Effect of Sex Hormones on Ventricular Ion Channels Ventricular Potassium Channels}

Potassium channels play a pivotal role in the regulation of muscle excitability. Potassium conductance through potassium channels present on the plasma membrane enables the membrane potential to reach the equilibrium potential of potassium, leading to hyperpolarization or accelerated repolarization of action potential in muscle cells. This results in a controlled cell excitability, elicited by various signals such as depolarization of membrane potential, ligand-binding, and so on (26). Sex hormones can regulate these via modulation of gene expression (by binding to their unique nuclear receptor) or non-genomic pathways after binding to membrane receptors. The rapid non-genomic effects of sex hormones are exerted through the activation of specific signaling pathways, which are initiated from sex hormone receptors or binding proteins in the plasma membrane and cytosol. Furthermore, sex hormones may also directly bind to potassium channels or the auxiliary subunits to modulate the activities of potassium channel blockers and potassium channel openers.

Several different types of currents pass through the potassium channels, i.e., the transient outward current $\left(\mathrm{I}_{\text {to }}\right)$, the rapiddelayed rectifier current $\left(\mathrm{I}_{\mathrm{kr}}\right)$, the slow delayed-rectifier current $\left(\mathrm{I}_{\mathrm{ks}}\right)$, and the inward rectifier potassium current $\left(\mathrm{I}_{\mathrm{kl}}\right)$. However, there are contradicting reports concerning the interaction of sex hormones and the potassium channels. Previous studies either showed no influence of sex hormones on $\mathrm{I}_{\text {to }}(27)$ or greater expression in males than in females $(28,29)$. Consequently, an increased expression of this current was demonstrated in ovariectomized mice, with a concurrent increase in their associated channel mRNA (30). This has been confirmed by the fact that in the high estradiol state (as is pregnancy), a reduction of $\mathrm{I}_{\text {to }}$ is observed (31).

Similarly to the $\mathrm{I}_{\mathrm{to}}$, the $\mathrm{I}_{\mathrm{kr}}$ has also been shown to be either not influenced by gender (29), or less expressed in females (32). This was confirmed in an in vitro study upon acute administration of exogenous estradiol on cultured guinea pig cardiomyocytes with human ether-a-go-go-related gene (hERG) overexpression, which unmasked the blockage of the hERG channel and thus 


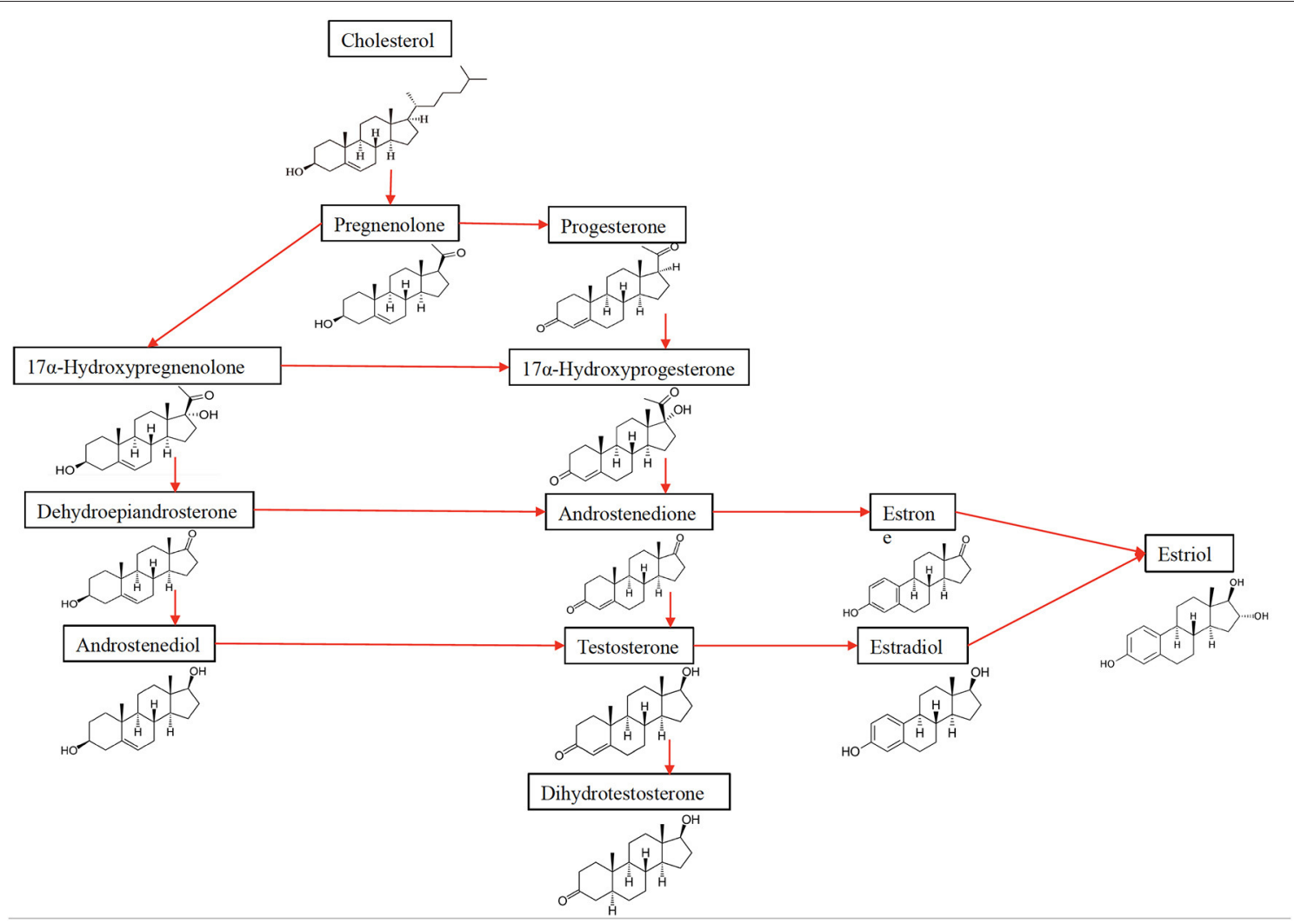

FIGURE 2 | The synthesis of sex hormones from their precursor cholesterol.

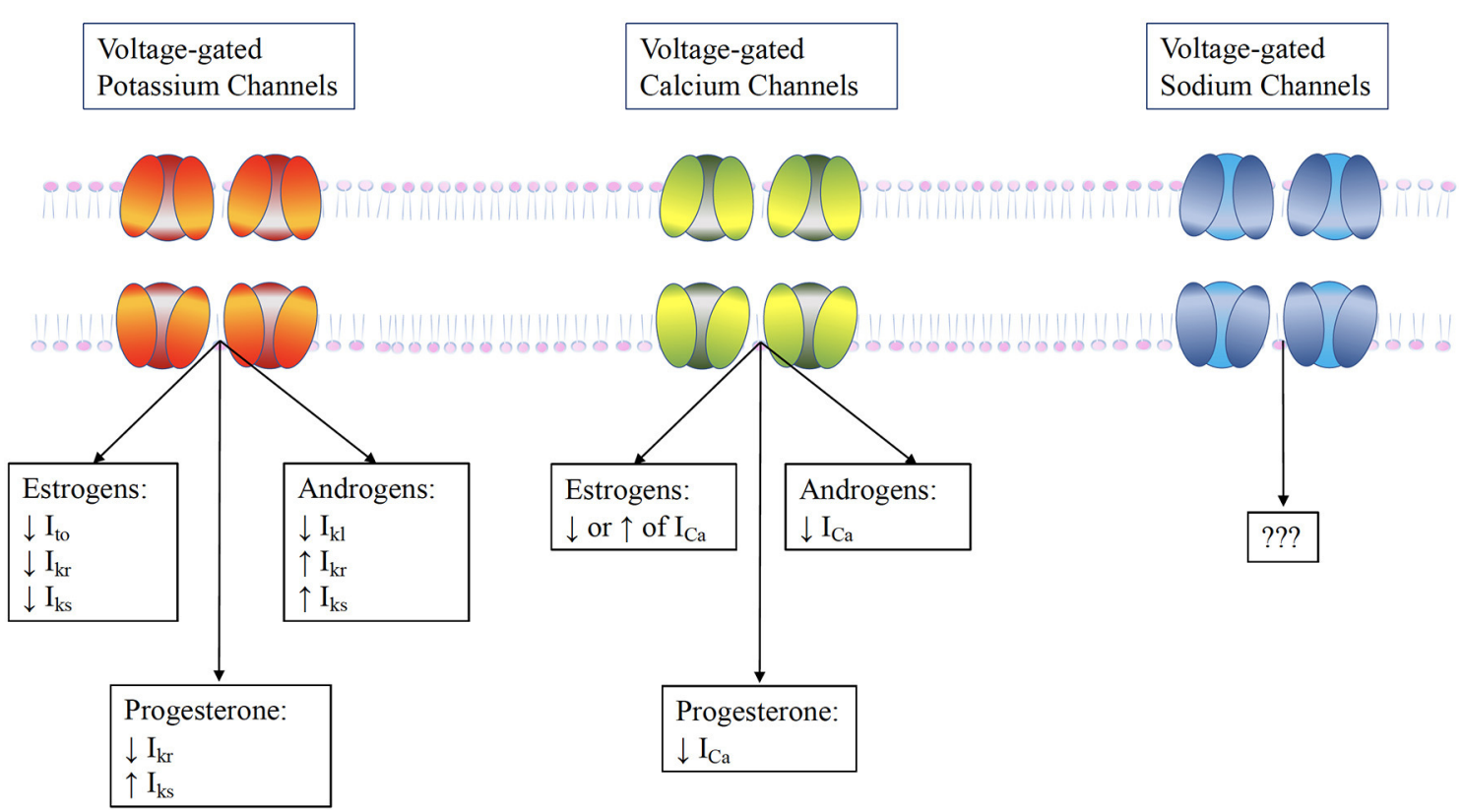

FIGURE 3 | The influence of sex hormones on ventricular ion channels. Testosterone increases repolarizing currents $I_{\mathrm{kr}}$ and $I_{\mathrm{ks}}$ and the $I_{\mathrm{to}}$, while it acutely increases the L-type calcium current $I_{\mathrm{CaL}}$. Estrogen has a more complex effect. It directly blocks the $\mathrm{I}_{\mathrm{kr}}$, but may also increase it by promoting HERG trafficking. Furthermore, it reduces the KCNE1, thereby reducing $\mathrm{I}_{\mathrm{ks}}$. These alterations result in prolongation of AP duration by estrogens, but its shortening by testosterone. 
$I_{k r}$ (33). In various animal models, the $I_{k s}$ has been observed as either larger in males (34), larger in females or with no gender difference at all (29), depending on which region the cells were taken from. This is in line with increasing evidence suggesting that the differences exerted by sex hormones may not be uniform across the heart. As in the case of $\mathrm{I}_{\mathrm{kr}}$, this current has also been shown to be blocked upon administration of exogenous estradiol through blockage of its related channels (KCNQ1/KCNE1) (35). Interestingly, while this current is enhanced by progesterone, as shown in the in vitro patch clamping study by Nakamura et al. (36) the hERG channel trafficking is reduced with progesterone. Furthermore, it has been demonstrated in guinea pig ventricular myocytes through acute applications of physiological serum levels of testosterone that this increases the outward potassium currents $\left(\mathrm{I}_{\mathrm{kr}}\right.$ and $\left.\mathrm{I}_{\mathrm{ks}}\right)$ and the inward rectifier current $\left(\mathrm{I}_{\mathrm{kl}}\right)(7)$. Thus, progesterone and testosterone shorten the ventricular APs, while estrogen lengthens the APs and may exert a pro-arrhythmic effect (8).

\section{Ventricular Calcium Channels}

The L-type $\mathrm{Ca}^{2+}$ channels are heteromultimeric proteins, consisting of multiple subunits. Similar to the mechanism with the above-mentioned potassium channels, signaling of gonadal steroids has traditionally been associated to a genomic action, i.e., the transcriptional control of target genes through binding of the nuclear receptors and ligands to the genomic consensus sequence in reproductive organs. However, several biological actions of gonadal steroids have recently been shown to be too rapid to be compatible with transcriptional mechanisms.

The evidence on interaction of sex hormones and the cardiac calcium channels is conflicting. In fact, there are reports of increased (29), decreased (32), or indifferent calcium currents $\left(\mathrm{I}_{\mathrm{Ca}}\right)$ in females as compared to males (27). Similarly to what was observed for the cardiac potassium channels, there is evidence of regional heterogeneity in the different interactions between sex hormones and ion channels (37). In fact, in animal studies, gender differences were observed for the $\mathrm{I}_{\mathrm{Ca}}$ in the apex, but not in the base of the left ventricle of rabbits (37). Moreover, an increase in L-type calcium channels was shown in the basal cardiomyocytes of rabbits by incubating these with physiological concentrations of estrogen. This effect, however, was not seen in the apical cardiomyocytes (38). Acute administration of progesterone was shown to decrease the $\mathrm{I}_{\mathrm{Ca}}$ by $60 \%$ (8). Interestingly, ovariectomized mice had an increase in the expression of L-type calcium channels, which were reversed upon administration of exogenous estrogen (39). Testosterone also plays a part in the modulation of the voltage-gated calcium channels. It is a selective and potent inhibitor of L-type calcium channels of vascular smooth muscles (40). The likely reason may be the fact that it blocks the major $\alpha_{1}$ subunit of the Ltype channel, similarly to the effects of the commonly prescribed calcium channel antagonists.

\section{Ventricular Sodium Channels}

The influence of sex hormones on the cardiac sodium channels are yet unknown. Even though there is no reported association between sex hormones and the LQT3 (41), there is increasing evidence linking sex hormones to the phenotypic expression of the Brugada Syndrome (42), despite the fact that both diseases stem from cardiac sodium channel mutations. The interesting link between the Brugada Syndrome and sex hormones is thoroughly discussed in the later section.

\section{Ventricular Ryanodine Receptor}

The contractile function of the heart is determined by intracellular calcium concentration, which is influenced by the expression and activity of calcium regulatory proteins. When the sarcolemma is depolarized, the voltage-gated Ltype calcium channels are opened and the influx of calcium into cytosol increases. This influx induces a massive release of calcium from the sarcoplasmic reticulum via the ryanodine receptor (RyR). This results in a sudden increase in calcium, which then triggers cardiac contraction. Tsang et al. (43) demonstrated how testosterone increased contraction and relaxation velocities that were associated with increased calcium release and recovery through activities of the RyR receptor and sarcoendoplasmic reticulum calcium transport ATPase (SERCA2). This observation may explain the predominantly male phenotype in catecholaminergic polymorphic ventricular tachycardia (CPVT).

\section{SEX HORMONES AND VENTRICULAR ARRHYTHMIAS}

Sex hormones may alter the susceptibility to ventricular tachyarrhythmias in patients with underlying structural heart disease and in those with cardiac channelopathies.

\section{Coronary Artery Disease}

The higher incidence of coronary artery disease, and especially of $\mathrm{SCD}$, in male patients but also in females following menopause, has highlighted the role of estrogen as a cardioprotective hormone. It was shown that estrogen has beneficial effects by improving cardiac function, preserving calcium homeostasis and inhibiting the mitochondrial apoptotic pathway (44). In the context of an ischemic insult to the heart, reperfusion that accompanies the opening of a blocked coronary artery may trigger arrhythmias and result in SCD. Estrogen was shown to decrease reperfusion arrhythmias in multiple animal studies. Savergnini et al. (45) demonstrated in young female rats that administration of estradiol was protective against this type of arrhythmia. This finding was also confirmed by Wang et al. (46) who showed that this action was mediated by the genomic action of estrogen, mainly the upregulation of the Estrogen Receptor $\beta$ $(\operatorname{Er} \beta)$ activation.

The role of testosterone during cardiac ischemia and in the prevention of reperfusion arrhythmias is controversial. Preclinical studies showed that pretreatment with testosterone of rat hearts exposed to ischemia decreased arrhythmias, as effectively as it was the case after estradiol administration (47). Likewise, testosterone replacement was shown to exert cardioprotective effects in orchiectomized rats (48). In another study in isolated rat hearts exposed to acute ischemia, 
testosterone significantly reduced norepinephrine release and consequent arrhythmias (49).

\section{Arrhythmogenic Cardiomyopathy}

Arrhythmogenic right ventricular cardiomyopathy (ARVC) is an inherited heart disease that is associated with life-threatening ventricular arrhythmias. It is one of the leading causes of SCD, especially in the young, athletic population (50). While risk stratification traditionally relied on measurements of structural dysfunction and electrophysiological indices (51), there have been recent attempts to identify circulating biomarkers for prediction of arrhythmic risk. Among these, sex hormones, and particularly testosterone, seem to play an important role in arrhythmogenesis. In the study by Akdis et al. (52) our group investigated the role of sex hormones and their association with major arrhythmic cardiac events (MACE) in patients with ARVC. We observed that elevated serum testosterone levels were independently associated with MACE in male ARVC patients, whereas estradiol levels were significantly lower in female patients with MACE. These findings have recently been validated in another study by Ren et al. (53) in a different ARVC cohort. The study showed that testosterone levels were a strong predictor of future adverse arrhythmic events in male patients with ARVC, independently from baseline systolic function. However, there was no association between the circulating levels of sex hormones and future heart failure events.

It is important to note that SCD may occur during early, clinically occult stage of ARVC, which still bears the pathological hallmarks of progressive cardiomyocyte loss and fibrofatty infiltration. Hence, there is an underlying electrophysiological substrate in ARVC that can facilitate reentry. This is in contrast with the mechanisms of arrhythmogenesis in patients with outflow tract ventricular tachyarrhythmias in the absence of structural heart disease. The study by $\mathrm{Hu}$ et al. (54) did not reveal any differences in circulating testosterone levels between diseased and control males with such idiopathic arrhythmias, while estradiol levels were indeed lower in diseased males. While the proarrhythmogenic effect of testosterone in ARVC may be partially related to increased apoptosis and lipogenesis, as shown in the study by Akdis et al. (52) arrhythmia susceptibility in patients with idiopathic outflow tract tachyarrhythmias may be due to estrogen deficiency and its consequences on the cardiac calcium and potassium channels, as discussed previously.

\section{Takotsubo Syndrome}

Takotsubo Syndrome is characterized by acute and mostly transient left ventricular dysfunction, which is often preceded by emotional or physical triggers. The patients have a substantial risk for MACE (55). The fact that this condition typically occurs in post-menopausal women (up to $90 \%$ of cases) has pointed out the role of estrogen deficiency as a causal factor, although pathophysiological mechanisms underlying the disease are still largely debated. The lack of estrogen together with an excess in catecholamines may not only underlie the pathophysiology of the disease itself, but also the risk of arrhythmic complications. This has been shown in a small study by El-Battrawy et al. (56) on hiPSC-CMs, which demonstrated that catecholamine excess may increase reactive oxygen species (ROS) production, which in turn enhances the late sodium current $\left(\mathrm{I}_{\mathrm{Na}}\right)$ and suppresses the $\mathrm{I}_{\mathrm{to}}$, causing prolongation of AP duration. Interestingly, when these hiPSC-CMs were treated with estradiol, this reduced their sensitivity to catecholamines by reducing adrenoreceptor expression, and thus, showed a protective effect of estrogen in the context of this disease. Further studies are needed to determine the exact pathophysiologic and prognostic role of sex hormones in Takotsubo Syndrome.

\section{Cardiac Channelopathies Long QT Syndrome (LQTS)}

This condition defines prolonged rate-corrected QT intervals (QTc) in patients who are at risk for ventricular tachyarrhythmias (typically TdP) and SCD (36). LQTS can be either congenital or acquired (as is the case for drug-induced LQTS). Female sex is known to be an independent risk factor, as females have $10-20 \mathrm{~ms}$ longer QTc intervals. However, the gender difference only manifests after puberty, suggesting that female sex hormones may play a role in the increased propensity for arrhythmias $(36,57,58)$.

The QTc is most affected by alterations in phase 2 and 3 of the AP, which are dominated, respectively, by the L-type calcium current (upregulation lengthens the QTc) and the delayed rectifier potassium currents $\left(\mathrm{I}_{\mathrm{kr}}\right.$ and $\mathrm{I}_{\mathrm{ks}}$ upregulation shortens the QTc). As mentioned previously, estrogen, progesterone and testosterone have varying effects on these currents, which could explain the gender differences (7). While the hypothesis that increased estrogen might be responsible for arrhythmogenesis in females has not been proven in humans yet, there are several clinical studies showing that QTc and arrhythmogenicity may increase in in males with decreased testosterone. A recent study by Salem et al. (59) has reported that male hypogonadism secondary to androgen-deprivation therapies (ADTs) is associated with acquired LQTS and increased incidence of TdP. Furthermore, the same group has also studied hiPSCs from men and treated them either with ADTs and dihydrotestosterone, reporting that while the ADTs indeed prolonged the QT interval, this was acutely reversed upon dihydrotestosterone administration (60).

\section{Brugada Syndrome}

This genetically-determined disease is characterized by the appearance of a coved-type ST segment elevation in the right precordial ECG leads, and puts the patients at significant risk for SCD in the absence of an underlying structural heart disease (61). The most common genetic mutations found in affected patients (up to 25\%) are loss-of-function mutations in the SCN5A gene, which encodes the $\alpha$ subunit of the cardiac sodium channel protein $\left(\mathrm{Nav}_{1.5}\right)$ (62). Despite the autosomal dominant inheritance of the disease, its incidence is significantly higher in males (8:1 in Western countries and 9:1 in Asia). Indeed, a study by Shimizu et al. (42) showed that males with the Brugada Syndrome had significantly higher testosterone levels as compared to their control counterparts, even after adjusting for age, exercise, stress, smoking habits, and medications. Furthermore, there are a few interesting case reports correlating 
the Brugada ECG pattern to blood testosterone levels. Matsuo et al. (63) described two cases of males with an asymptomatic Brugada ECG pattern, which disappeared following surgical castration for prostate cancer. Another recently published case study by Sichrovsky et al. (64) has demonstrated the development of a previously unrecognized Brugada pattern and SCD in a genetic female living as a transgender male through the use of exogenous testosterone.

As previous literature has suggested, the accentuation of the epicardial AP notch and loss of its dome induced by a potassium channel opener, seems to be the cause of the typical Brugadatype ST segment elevation. This can result in phase II reentry and trigger ventricular tachycardia or ventricular fibrillation (65). Moreover, it matches the evidence of the sodium channel being the primary gene candidate for the Brugada Syndrome. Since either a decrease in the density or an acceleration of inactivation of the sodium channel would leave $\mathrm{I}_{\text {to }}$ unopposed during the early phases of the AP, the mechanism of the AP notch accentuation may indeed be due to a more prominent $\mathrm{I}_{\text {to }}$, which is physiologically more expressed in males as compared to females. This has been proven in a dog model, showing that the $\mathrm{I}_{\text {to }}$ current density of the RV epicardium is significantly higher in males than in females, culminating in increased transmural dispersion of repolarization (4). This substrate facilitates the presence of the Brugada-type ECG pattern and occurrence of arrhythmias in males. Furthermore, as previously mentioned, testosterone may augment outward repolarizing currents (such as $\mathrm{I}_{\mathrm{kr}}$ and $\mathrm{I}_{\mathrm{ks}}$ ), and thus, lead to loss of the AP dome, explaining the male predominance of the Brugada Syndrome. A recently published in vitro study by Yang et al. (66) examining the effects of estrogen and testosterone on the wild-type and the mutant $\mathrm{Nav}_{1.5}$ has shown no influence of these hormones on either channel, but this study had the limitation of lacking an in vivo validation.

\section{Catecholaminergic Polymorphic Ventricular Tachycardia}

CPVT is an inherited arrhythmic syndrome, which affects 1 in 10,000 individuals. It is characterized by potentially lethal ventricular arrhythmias, which are often biventricular or polymorphic in origin, and which mostly appear following an adrenergic challenge precipitated by emotional or physical stress (67). CPVT arises from disrupted intracellular calcium homeostasis and is most often associated with gene abnormalities involving the RyR2. The resulting dysregulated RyR2-mediated leak of sarcoplasmic reticular calcium elevates cytosolic calcium, increasing electrogenic sodium/calcium exchanger and/or calcium-activated chloride transient inward currents. The consequently occurring delayed afterdepolarizations may trigger arrhythmic events. Interestingly, the majority of phenotypes related to $R y R 2$ mutations show a higher mortality in males as compared to females. The molecular basis for this entity has been explored in a recent study by Saadeh et al. (68) in a murine model of CPVT (homozygotic RyR2 $2^{\mathrm{S} / \mathrm{S}}$ ), in which they investigated the impact of gender on the expression levels of molecular determinants of calcium homeostasis and conduction velocity. While the authors have found no difference in the expression levels of calcium homeostasis proteins, they showed a decreased
Cx43 expression, which correlated with slowed conduction velocity in female mice, but not in males.

\section{HORMONE REPLACEMENT THERAPY AND ARRHYTHMIAS}

Male hypogonadism, which may arise from multiple etiologies including androgen-deprivation therapy (ADT), has been reported as a risk factor for acquired LQTS and the occurrence of TdP. This has led to multiple pharmacovigilance studies assessing the link between hormone replacement therapy (HRT) and the incidence of ventricular arrhythmias. Interestingly, this has helped to shed some light on the link between arrhythmias and sex hormones, supporting the hypothesis that hypogonadism is a correctable and identifiable risk factor for TdP, especially in men. This has clinical implications, for example while considering ADT, which is the cornerstone of the treatment of prostate cancer.

\section{Ventricular Arrhythmias}

Male hypogonadism is a condition in which clinical symptoms occur due to testosterone deficiency (69). As discussed previously, low testosterone values may be associated with a higher risk of ventricular arrhythmias and SCD due to a lengthening of the myocardial repolarization phase. In fact, the QTc values of males after puberty are significantly shorter and aging men with decreasing testosterone levels seem to have a gradual increase in QTc. Some types of male hypogonadism can be treated with testosterone replacement therapy (TRT). The data available on the effects of TRT on cardiovascular risks are contradicting. The RHYME study, which investigated hypogonadal men receiving TRT, did not find any increased cardiovascular risk (70). The same results were shown in a systematic review by Corona et al. (71) which reported the absence of a causal role between TRT and cardiovascular events. Interestingly, a study by Muensterman et al. (58) reported that in older men, the use of transdermal testosterone combined with oral progesterone attenuates drug-induced QTc lengthening. This shows that there may be a probable protective role of both testosterone and progesterone on arrhythmia occurrence due to prolonged QTc.

Concerning hormone replacement in females, there are several studies in post-menopausal women showing that estrogen replacement therapy (ERT) prolongs the QTc interval. Indeed, as mentioned above, estrogen has a lengthening effect on the myocardial repolarization phase. This effect is not evident in female children, but only manifests itself after adolescence, and significantly decreases after menopause (72). A study on hormone replacement for 1 year confirmed that the use of ERT increases the QTc interval (73). Interestingly, this effect was not seen in combined estrogen-progestin replacement therapies, strengthening the theory that progesterone most likely has a similar effect on the QTc interval as testosterone. It is important to note that a study by Saba et al. (74) did not find any significant difference in QTc interval between premenopausal, post-menopausal and post-menopausal women treated with hormone replacement. A major limitation of this study was 
that it was not clear whether hormone replacement consisted of estrogen alone or combined with progesterone in the study population (74).

\section{CONCLUSIONS}

Gender is known to be an independent risk factor for some types of cardiac arrhythmias. However, the link between the sex hormones and susceptibility to arrhythmias is still a matter of debate. Nonetheless, despite conflicting results, these hormones may influence arrhythmia occurrence both in the presence or absence of underlying structural heart disease. Further studies, which validate or contradict the already present literature, will be of invaluable importance to fully understand the pathophysiological mechanisms that lie at the basis of arrhythmogenesis.

\section{REFERENCES}

1. Fu D. Cardiac Arrhythmias: diagnosis, symptoms, and treatments. Cell Biochem Biophys. (2015) 73:291-6. doi: 10.1007/s12013-015-0626-4

2. Wellens HJJ, Schwartz PJ, Lindemans FW, Buxton AE, Goldberger JJ, Hohnloser SH, et al. Risk stratification for sudden cardiac death: current status and challenges for the future. Eur Heart J. (2014) 35:1642-51. doi: 10.1093/eurheartj/ehu176

3. Magnani JW, Moser CB, Murabito JM, Sullivan LM, Wang N, Ellinor PT, et al. Association of sex hormones, aging, and atrial fibrillation in men: the framingham heart study. Circ Arrhythm Electrophysiol. (2014) 7:307-12. doi: 10.1161/CIRCEP.113.001322

4. Di Diego JM, Cordeiro JM, Goodrow RJ, Fish JM, Zygmunt AC, Pérez GJ, et al. Ionic and cellular basis for the predominance of the brugada syndrome phenotype in males. Circulation. (2002) 106:2004-11. doi: 10.1161/01.CIR.0000032002.22105.7A

5. Meyer S, van der Meer P, van Tintelen JP, van den Berg MP. Sex differences in cardiomyopathies: Sex difffferences in cardiomyopathies. Eur J Heart Fail. (2014) 16:238-47. doi: 10.1002/ejhf.15

6. Furukawa T, Kurokawa J. Regulation of cardiac ion channels via nongenomic action of sex steroid hormones: implication for the gender difference in cardiac arrhythmias. Pharmacol Ther. (2007) 115:106-15. doi: 10.1016/j.pharmthera.2007.04.008

7. Bai CX, Kurokawa J, Tamagawa M, Nakaya H, Furukawa T. Nontranscriptional regulation of cardiac repolarization currents by testosterone. Circulation. (2005) 112:1701-10. doi: 10.1161/CIRCULATIONAHA.104.523217

8. Kurokawa J, Furukawa T. Non-genomic action of sex steroid hormones and cardiac repolarization. Biol Pharm Bull. (2013) 36:8-12. doi: 10.1248/bpb.b212021

9. Mangelsdorf DJ, Thummel C, Beato M, Herrlich P, Schütz G, Umesono $\mathrm{K}$, et al. The nuclear receptor superfamily: the second decade. Cell. (1995) 83:835-9. doi: 10.1016/0092-8674(95)90199-X

10. González-Sales M, Barrière O, Tremblay P-O, Nekka F, Desrochers J, Tanguay M. Modeling testosterone circadian rhythm in hypogonadal males: effect of age and circannual variations. AAPS J. (2016) 18:217-27. doi: 10.1208/s12248-015-9841-6

11. Gupta SK, Lindemulder EA, Sathyan G. Modeling of circadian testosterone in healthy men and hypogonadal men. J Clin Pharmacol. (2000) 40:731-8. doi: 10.1177/00912700022009486

12. Smith RP, Coward RM, Kovac JR, Lipshultz LI. The evidence for seasonal variations of testosterone in men. Maturitas. (2013) 74:208-12. doi: 10.1016/j.maturitas.2012.12.003

13. Feldman HA, Longcope C, Derby CA, Johannes CB, Araujo AB, Coviello $\mathrm{AD}$, et al. Age trends in the level of serum testosterone and other hormones

\section{AUTHOR CONTRIBUTIONS}

SC manuscript drafting and data collection. AS manuscript drafting and review. AG and DA data collection and manuscript review. CB funding recruitment and manuscript review. FD coordinator, manuscript structuring, and manuscript review. All authors contributed to the article and approved the submitted version.

\section{FUNDING}

The Zurich ARVC Program was supported by grants from the Georg and Bertha Schwyzer-Winiker Foundation, the Baugarten Foundation, the Leone-Wild Charitable Foundation, the Swiss Heart Foundation, and the Swiss National Science Foundation.

in middle-aged men: longitudinal results from the massachusetts male aging study. J Clin Endocrinol Metab. (2002) 87:589-98. doi: 10.1210/jcem.87.2.8201

14. Bao A, Liu R, van Someren E, Hofman M, Cao Y, Zhou J. Diurnal rhythm of free estradiol during the menstrual cycle. Eur J Endocrinol. (2003) 148:227-32. doi: $10.1530 /$ eje. 0.1480227

15. Cano Sokoloff N, Misra M, Ackerman KE. Exercise, training, and the hypothalamic-pituitary-gonadal axis in men and women. Frontiers of Hormone Research. (2016) 47:27-43. doi: 10.1159/000445154

16. Di Luigi L, Romanelli F, Sgrò P, Lenzi A. Andrological aspects of physical exercise and sport medicine. Endocrine. (2012) 42:278-84. doi: 10.1007/s12020-012-9655-6

17. Grandys M, Majerczak J, Zapart-Bukowska J, Kulpa J, Zoladz JA. Gonadal hormone status in highly trained sprinters and in untrained men. J Strength Cond Res. (2011) 25:1079-84. doi: 10.1519/JSC.0b013e3181d $4 \mathrm{~d} 3 \mathrm{f} 4$

18. FitzGerald LZ, Robbins WA, Kesner JS, Xun L. Reproductive hormones and interleukin-6 in serious leisure male athletes. Eur J Appl Physiol. (2012) 112:3765-73. doi: 10.1007/s00421-012-2356-2

19. Nindl BC, Kraemer WJ, Gotshalk LA, Marx JO, Volek JS, Bush JA, et al. Testosterone responses after resistance exercise in women: influence of regional fat distribution. Int J Sport Nutr Exerc Metab. (2001) 11:451-65. doi: 10.1123/ijsnem.11.4.451

20. Patel C, Burke JF, Patel H, Gupta P, Kowey PR, Antzelevitch C, et al. Is there a significant transmural gradient in repolarization time in the intact heart?: cellular basis of the t wave: a century of controversy. Circ Arrhythm Electrophysiol. (2009) 2:80-8. doi: 10.1161/CIRCEP.108.791830

21. Rosenbaum D. Quantitative Cardiac Electrophysiology. Boca Raton, FL: CRC Press (2002). doi: 10.1201/b14064

22. Bett GCL. Hormones and sex differences: changes in cardiac electrophysiology with pregnancy. Clin Sci. (2016) 130:747-59. doi: 10.1042/CS20150710

23. Marcus FI, McKenna WJ, Sherrill D, Basso C, Bauce B, Bluemke DA, et al. Diagnosis of arrhythmogenic right ventricular cardiomyopathy/dysplasia: proposed modification of the task force criteria. Circulation. (2010) 121:153341. doi: 10.1161/CIRCULATIONAHA.108.840827

24. Surawicz B, Parikh SR. Prevalence of male and female patterns of early ventricular repolarization in the normal ECG of males and females from childhood to old age. J Am Coll Cardiol. (2002) 40:1870-6. doi: 10.1016/S0735-1097(02)02492-0

25. Lizotte E, Grandy SA, Tremblay A, Allen BG, Fiset C. Expression, distribution and regulation of sex steroid hormone receptors in mouse heart. Cell Physiol Biochem. (2009) 23:75-86. doi: 10.1159/000204096

26. Sakamoto K, Kurokawa J. Involvement of sex hormonal regulation of $\mathrm{K}^{+}$channels in electrophysiological and contractile functions of muscle tissues. J Pharmacol Sci. (2019) 139:259-65. doi: 10.1016/j.jphs.2019. 02.009 
27. Trépanier-Boulay V, St-Michel C, Tremblay A, Fiset C. Gender-based differences in cardiac repolarization in mouse ventricle. Circ Res. (2001) 89:437-44. doi: 10.1161/hh1701.095644

28. Saito T, Ciobotaru A, Bopassa JC, Toro L, Stefani E, Eghbali M. Estrogen contributes to gender differences in mouse ventricular repolarization. Circ Res. (2009) 105:343-52. doi: 10.1161/CIRCRESAHA.108.190041

29. Xiao L, Zhang L, Han W, Wang Z, Nattel S. Sex-based transmural differences in cardiac repolarization and ionic-current properties in canine left ventricles. Am J Physiol-Heart Circ Physiol. (2006) 291:H570-80. doi: 10.1152/ajpheart.01288.2005

30. El Gebeily G, El Khoury N, Mathieu S, Brouillette J, Fiset C. Estrogen regulation of the transient outward $\mathrm{K}^{+}$current involves estrogen receptor $\alpha$ in mouse heart. J Mol Cell Cardiol. (2015) 86:85-94. doi: 10.1016/j.yjmcc.2015.07.013

31. Eghbali M, Deva R, Alioua A, Minosyan TY, Ruan H, Wang Y, et al. Molecular and functional signature of heart hypertrophy during pregnancy. Circ Res. (2005) 96:1208-16. doi: 10.1161/01.RES.0000170652.71414.16

32. James AF, Arberry LA, Hancox JC. Gender-related differences in ventricular myocyte repolarization in the guinea pig. Basic Res Cardiol. (2004) 99:183-92. doi: 10.1007/s00395-003-0451-6

33. Kurokawa J, Tamagawa M, Harada N, Honda S, Bai C-X, Nakaya $\mathrm{H}$, et al. Acute effects of oestrogen on the guinea pig and human $\mathrm{I}_{\mathrm{Kr}}$ channels and drug-induced prolongation of cardiac repolarization: effects of oestrogen on the hERG channel. J Physiol. (2008) 586:2961-73. doi: 10.1113/jphysiol.2007.150367

34. Zhu Y, Ai X, Oster RA, Bers DM, Pogwizd SM. Sex differences in repolarization and slow delayed rectifier potassium current and their regulation by sympathetic stimulation in rabbits. Pflüg Arch Eur J Physiol. (2013) 465:805-18. doi: 10.1007/s00424-012-1193-9

35. Möller C, Netzer R. Effects of estradiol on cardiac ion channel currents. Eur J Pharmacol. (2006) 532:44-9. doi: 10.1016/j.ejphar.2006.01.006

36. Nakamura H, Kurokawa J, Bai CX, Asada K, Xu J, Oren RV, et al. Progesterone regulates cardiac repolarization through a nongenomic pathway: an in vitro patch-clamp and computational modeling study. Circulation. (2007) 116:2913-22. doi: 10.1161/CIRCULATIONAHA.107.702407

37. Yang X, Chen G, Papp R, DeFranco DB, Zeng F, Salama G. Oestrogen upregulates L-type $\mathrm{Ca}^{2+}$ channels via oestrogen-receptor- $\alpha$ by a regional genomic mechanism in female rabbit hearts: regional genomic upregulation of $I_{\mathrm{Ca}, \mathrm{L}}$ by oestrogen via ER $\alpha$. J Physiol. (2012) 590:493-508. doi: 10.1113/jphysiol.2011.219501

38. Sims C, Reisenweber S, Viswanathan PC, Choi BR, Walker WH, Salama G. Sex, age, and regional differences in l-type calcium current are important determinants of arrhythmia phenotype in rabbit hearts with drug-induced long QT type 2. Circ Res. (2008) 102:86-100. doi: 10.1161/CIRCRESAHA.108.173740

39. Chu SH, Goldspink P, Kowalski J, Beck J, Schwertz DW. Effect of estrogen on calcium-handling proteins, $\beta$-adrenergic receptors, and function in rat heart. Life Sci. (2006) 79:1257-67. doi: 10.1016/j.lfs.2006.03.037

40. Scragg JL, Jones RD, Channer KS, Jones TH, Peers C. Testosterone is a potent inhibitor of L-type $\mathrm{Ca}^{2+}$ channels. Biochem Biophys Res Commun. (2004) 318:503-6. doi: 10.1016/j.bbrc.2004.04.054

41. Nakagawa M, Ooie T, Takahashi N, Taniguchi Y, Anan F, Yonemochi H, et al. Influence of menstrual cycle on QT interval dynamics. Pacing Clin Electrophysiol. (2006) 29:607-13. doi: 10.1111/j.1540-8159.2006.00407.x

42. Shimizu W, Matsuo K, Kokubo Y, Satomi K, Kurita T, Noda T, et al. Sex hormone and gender difference-role of testosterone on male predominance in brugada syndrome. J Cardiovasc Electrophysiol. (2007) 18:415-21. doi: 10.1111/j.1540-8167.2006.00743.x

43. Tsang S, Wong SSC, Wu S, Kravtsov GM, Wong T-M. Testosteroneaugmented contractile responses to $\alpha_{1}$ - and $\beta_{1}$-adrenoceptor stimulation are associated with increased activities of RyR, SERCA, and NCX in the heart. Am J Physiol-Cell Physiol. (2009) 296:C766-82. doi: 10.1152/ajpcell.00193.2008

44. Sivasinprasasn S, Shinlapawittayatorn K, Chattipakorn SC, Chattipakorn N. Estrogenic impact on cardiac ischemic/reperfusion injury. J Cardiovasc Transl Res. (2016) 9:23-39. doi: 10.1007/s12265-016-9675-3

45. Savergnini SQ, Reis AM, Santos RAS, Santos PEB, Ferreira AJ, Almeida AP. Effects of short-term administration of estradiol on reperfusion arrhythmias in rats of different ages. Braz J Med Biol Res. (2012) 45:1248-54. doi: 10.1590/S0100-879X2012007500169

46. Wang Y, Wang Q, Zhao Y, Gong D, Wang D, Li C, et al. Protective effects of estrogen against reperfusion arrhythmias following severe myocardial ischemia in rats. Circ J. (2010) 74:634-43. doi: 10.1253/circj.CJ-09-0223

47. Kuhar P, Lunder M, Drevenšek G. The role of gender and sex hormones in ischemic-reperfusion injury in isolated rat hearts. Eur J Pharmacol. (2007) 561:151-9. doi: 10.1016/j.ejphar.2007.01.043

48. Pongkan W, Chattipakorn SC, Chattipakorn N. Chronic testosterone replacement exerts cardioprotection against cardiac ischemia-reperfusion injury by attenuating mitochondrial dysfunction in testosterone-deprived rats. PLoS ONE. (2015) 10:e0122503. doi: 10.1371/journal.pone.0122503

49. Wang X, Zhang Y, Bu J, Shen L, He B. Effects of testosterone on norepinephrine release in isolated rat heart. J Huazhong Univ Sci Technolog Med Sci. (2012) 32:42-46. doi: 10.1007/s11596-012-0007-9

50. Corrado D, Link MS, Calkins H. Arrhythmogenic right ventricular cardiomyopathy. N Engl J Med. (2017) 376:61-72. doi: 10.1056/NEJMra1509267

51. Cadrin-Tourigny J, Bosman LP, Nozza A, Wang W, Tadros R, Bhonsale A, et al. A new prediction model for ventricular arrhythmias in arrhythmogenic right ventricular cardiomyopathy. Eur Heart J. (2019) 40:1850-58. doi: 10.1093/eurheartj/ehz103

52. Akdis D, Saguner AM, Shah K, Wei C, Medeiros-Domingo A, Eckardstein A von, et al. Sex hormones affect outcome in arrhythmogenic right ventricular cardiomyopathy/dysplasia: from a stem cell derived cardiomyocyte-based model to clinical biomarkers of disease outcome. Eur Heart J. (2017) 38:1498508. doi: 10.1093/eurheartj/ehx011

53. Ren J, Chen L, Zhang N, Chen X, Zhao Q, Chen K, et al. Plasma testosterone and arrhythmic events in male patients with arrhythmogenic right ventricular cardiomyopathy. ESC Heart Fail. (2020) 7:1547-59. doi: 10.1002/ehf2.12704

54. Hu X, Jiang H, Xu C, Zhou X, Cui B, Lu Z. Relationship between sex hormones and idiopathic outflow tract ventricular arrhythmias in adult male patients. Transl Res. (2009) 154:265-8. doi: 10.1016/j.trsl.2009.07.007

55. Borchert T, Hübscher D, Guessoum CI, Lam T-DD, Ghadri JR, Schellinger IN, et al. Catecholamine-dependent $\beta$-adrenergic signaling in a pluripotent stem cell model of takotsubo cardiomyopathy. J Am Coll Cardiol. (2017) 70:975-91. doi: 10.1016/j.jacc.2017.06.061

56. El-Battrawy I, Zhao Z, Lan H, Schünemann JD, Sattler K, Buljubasic F et al. Estradiol protection against toxic effects of catecholamine on electrical properties in human-induced pluripotent stem cell derived cardiomyocytes. Int J Cardiol. (2018) 254:195-202. doi: 10.1016/j.ijcard.2017.11.007

57. Piccirillo G, Moscucci F, Pofi R, D’Alessandro G, Minnetti M, Isidori AM, et al. Changes in left ventricular repolarization after short-term testosterone replacement therapy in hypogonadal males. J Endocrinol Invest. (2019) 42:1051-65. doi: 10.1007/s40618-019-01026-5

58. Muensterman ET, Jaynes HA, Sowinski KM, Overholser BR, Shen C, Kovacs RJ, et al. Effect of transdermal testosterone and oral progesterone on druginduced qt interval lengthening in older men: a randomized, double-blind, placebo-controlled crossover-design study. Circulation. (2019) 140:1127-9. doi: 10.1161/CIRCULATIONAHA.119.041395

59. Salem JE, Waintraub X, Courtillot C, Shaffer CM, Gandjbakhch E, Maupain $\mathrm{C}$, et al. Hypogonadism as a reversible cause of torsades de pointes in men. Circulation. (2018) 138:110-3. doi: 10.1161/CIRCULATIONAHA.118.034282

60. Salem JE, Yang T, Moslehi JJ, Waintraub X, Gandjbakhch E, Bachelot A, et al. Androgenic effects on ventricular repolarization: a translational study from the international pharmacovigilance database to iPSC-cardiomyocytes. Circulation. (2019) 140:1070-80. doi: 10.1161/CIRCULATIONAHA.119.040162

61. Brugada P, Brugada J. Right bundle branch block, persistent ST segment elevation and sudden cardiac death: a distinct clinical and electrocardiographic syndrome. J Am Coll Cardiol. (1992) 20:1391-6. doi: 10.1016/0735-1097(92)90253-J

62. Gourraud JB, Barc J, Thollet A, Le Scouarnec S, Le Marec H, Schott JJ, et al. The brugada syndrome: a rare arrhythmia disorder with complex inheritance. Front Cardiovasc Med. (2016) 3:9. doi: 10.3389/fcvm.2016.00009

63. Matsuo K, Akahoshi M, Seto S, Yano K. Disappearance of the brugada-type electrocardiogram after surgical castration. A role for testosterone and an 
explanation for the male preponderance? Pacing Clin Electrophysiol. (2003) 26:1551-3. doi: 10.1046/j.1460-9592.2003.t01-1-00227.x

64. Sichrovsky T, Mittal S. Brugada syndrome unmasked by use of testosterone in a transgender male: gender trumps sex as a risk factor. J Innov Card Rhythm Manag. (2019) 10:3526-9. doi: 10.19102/icrm.2019.100202

65. Yan GX, Antzelevitch C. Cellular basis for the brugada syndrome and other mechanisms of arrhythmogenesis associated with st-segment elevation. Circulation. (1999) 100:1660-6. doi: 10.1161/01.CIR.100.15.1660

66. Yang G, Liu J, Wang Y, Du Y, Ma A, Wang T. Lack of influence of sex hormones on Brugada syndrome-associated mutant Nav1.5 sodium channel. J Electrocardiol. (2019) 52:82-7. doi: 10.1016/j.jelectrocard.2018.11.011

67. Webster G, Berul CI. An update on channelopathies: from mechanisms to management. Circulation. (2013) 127:126-40. doi: 10.1161/CIRCULATIONAHA.111.060343

68. Saadeh K, Achercouk Z, Fazmin IT, Nantha Kumar N, Salvage SC, Edling $\mathrm{CE}$, et al. Protein expression profiles in murine ventricles modeling catecholaminergic polymorphic ventricular tachycardia: effects of genotype and sex. Ann N Y Acad Sci. (2020) 1478:63-74. doi: 10.1111/nyas.14426

69. Isidori AM, Giannetta E, Lenzi A. Male hypogonadism. Pituitary. (2008) 11:171-80. doi: 10.1007/s11102-008-0111-9

70. Maggi M, Wu FCW, Jones TH, Jackson G, Behre HM, Hackett G, et al. Testosterone treatment is not associated with increased risk of adverse cardiovascular events: results from the Registry of Hypogonadism in Men (RHYME). Int J Clin Pract. (2016) 70:843-52. doi: 10.1111/ijcp. 12876
71. Corona G, Maseroli E, Rastrelli G, Isidori AM, Sforza A, Mannucci E, et al. Cardiovascular risk associated with testosterone-boosting medications: a systematic review and meta-analysis. Expert Opin Drug Saf. (2014) 13:132751. doi: $10.1517 / 14740338.2014 .950653$

72. Yang P-C, Clancy CE. Effects of sex hormones on cardiac repolarization. J Cardiovasc Pharmacol. (2010) 56:123-9. doi: 10.1097/FJC.0b013e3181d6f7dd

73. Gökçe M, Karahan B, Yilmaz R, Örem C, Erdöl C, Özdemir S. Long term effects of hormone replacement therapy on heart rate variability, QT interval, QT dispersion and frequencies of arrhytmia. Int J Cardiol. (2005) 99:373-9. doi: 10.1016/j.ijcard.2003.03.030

74. Saba S, Link MS, Homoud MK, Wang PJ, Estes NAM. Effect of low estrogen states in healthy women on dispersion of ventricular repolarization. Am J Cardiol. (2001) 87:354-6. doi: 10.1016/S0002-9149(00)01377-1

Conflict of Interest: The authors declare that the research was conducted in the absence of any commercial or financial relationships that could be construed as a potential conflict of interest.

Copyright (c) 2021 Costa, Saguner, Gasperetti, Akdis, Brunckhorst and Duru. This is an open-access article distributed under the terms of the Creative Commons Attribution License (CC BY). The use, distribution or reproduction in other forums is permitted, provided the original author(s) and the copyright owner(s) are credited and that the original publication in this journal is cited, in accordance with accepted academic practice. No use, distribution or reproduction is permitted which does not comply with these terms. 